\title{
ДИНАМИКА ПОКАЗАТЕЛЕЙ ОКСИДАТИВНОГО СТАТУСА У КРОЛИКОВ (Oryctolagus cuniculus L.) ПРИ МОДЕЛИРОВАНИИ ТЕХНОЛОГИЧЕСКОГО СТРЕССА И ЕГО ФАРМАКОЛОГИЧЕСКОЙ КОРРЕКЦИИ
}

\author{
И.В. КИРЕЕВ, В.А. ОРОБЕЦ, Т.С. ДЕНИСЕНКО, Д.А. ЗИНЧЕНКО
}

\begin{abstract}
Стресс - одна из проблем животноводства, наносящая большой ущерб отрасли. К возникновению технологического стресса приводит множество факторов - от транспортировки до условий содержания и кормления животных. Развитие патологических состояний при стрессовых реакциях связано с интенсификацией свободнорадикальных процессов в организме и чрезмерным образованием свободных радикалов. Необходима разработка препаратов для фармакологической коррекции технологического стресса у животных на основе действующих веществ с антиоксидантной активностью и регламентов их применения в ветеринарии. Экспериментальные исследования провели в условиях моделирования технологического стресса (иммобилизация) у кроликов породы советская шиншилла возрастом 6-7 мес. В качестве средств профилактики животным вводили антиоксидантные и антистрессовые препараты, разработанные в Ставропольском государственном аграрном университете. Животные I группы служили контролем. Кроликам из II групाы вводили препарат для коррекции стрессовых состояний для сельскохозяйственных животных (Патент RU 2428992 от 20.09.11), из III группы - препарат Мебисел (Патент RU 2418579 от 20.05.11) (оба средства обладают выраженным антистрессовым действием), из IV - антиоксидантный препарат для животных (Патент RU 2435572 от 10.12.11), из V - препарат Полиоксидол (Патент RU 2538666 от 10.01.1.) (антиоксиданты). В крови определяли концентрацию кортизола, тироксина, показатели перекисного окисления липидов и антиоксидантной защиты. Установлено, что у подопытных животных иммобилизация спровоцировала значительное повышение синтеза кортизола, снижение количества тироксина, увеличение в 2,6 раза (p $\leq 0,01)$ концентрации диеновых конъюгатов в крови, малонового диальдегида - на $55,8 \%$ (p $\leq 0,01)$ и флуоресцирующих оснований Шиффа в 2,2 раза (p $\leq 0,01)$. Ограничение подвижности кроликов отрицательно отразилось на активности ферментативного звена антиоксидантной защиты (достоверное снижение активности глутатионпероксидазы на $35,2 \%$, супероксиддисмутазы - на $36,4 \%$, каталазы - на $40,7 \%, p \leq 0,01)$ и содержании восстановленного глутатиона на $33,3 \%$ (p $\leq 0,01)$. Введение антиоксидантных и антистрессовых препаратов кроликам способствовало нормализации исследуемых показателей у подопытных животных, значения которых на протяжении проведения эксперимента статистически достоверно отличались от зафиксированных в контрольной группе. Наиболее значимый рост концентрации кортизола у кроликов наблюдался через 1 сут после начала иммобилизации (в 5,8 раз), что можно считать пиком развития стресс-реакции, а уменьшение количества тироксина происходило постепенно на протяжении всего периода моделирования технологического стресса (до $60,9 \%, \mathrm{p} \leq \mathbf{0 , 0 1}$ ). В динамике активности антиоксидантных ферментов и продуктов перекисного окисления липидов наблюдались значительные различия между показателями животных из контрольной группы и кроликов, которые получали профилактические средства. У животных контрольной групшы наблюдалось прогрессирующее возрастание концентрации липопероксидов и снижение активности глутатионпероксидазы, супероксиддисмутазы, каталазы и количества восстановленного глутатиона. Использование антиоксидантных и антистрессовых препаратов перед началом иммобилизации (за 3 сут) способствовало оптимизации этих показателей, а примененные схемы профилактики позволили уменьшить негативное воздействие стресса, что выразилось в статистически достоверных различиях числовых значений результатов лабораторного исследования крови животных из II, III, IV и V опытных групा относительно контрольной группы: глутатионпероксидаза - повышение на 48,2-107,4 \%, p $\leq$ 0,01; супероксиддисмутаза - на $31,1-85,9 \%$, p $\leq 0,01$; каталаза - на 12,9-40,1 \%, p $\leq 0,05$ в III, IV и V группах; восстановленный глутатион - на $34,8-60,8 \%, p \leq 0,01$; тироксин - на 27,2-82,7 \%, p $\leq 0,05$; снижение концентрации кортизола на $83,5-207,0 \%$, p $\leq 0,01$; диеновых конъюгатов - на 37,2 $84,3 \%, \mathrm{p} \leq 0,01$; малонового диальдегида - на 26,1-46,9 \% (p $\leq 0,05)$ и флуоресцирующих оснований Шиффа - на $22,0-118,1 \%$ (p $\leq 0,05)$ к концу опыта. Применение препаратов ускорило постстрессовую адаптацию, что выражалось в увеличении среднесуточного прироста живой массы кроликов из опытных групп: во II группе - 28 г, в III группе -34 г, в IV групाе -36 г и в V группе - 38 г в сравнении с контрольной (24 г). Результаты эксперимента указывают на то, что вследствие стресс-реакции, об интенсивности которой можно судить по динамике стрессзависимых гормонов, происходят значительные изменения в функционировании системы антиок-
\end{abstract}


сидантной защиты и концентрации продуктов перекисного окисления липидов. На основании данных, полученных в эксперименте, рекомендуется фармакологическая коррекция технологического стресса с использованием предложенных транквилизаторов и антиоксидантных препаратов.

Ключевые слова: Oryctolagus cuniculus L., кролики, технологический стресс, иммобилизация, антистрессовый препарат, антиоксидантный препарат, антиоксидантная система, перекисное окисление липидов, гормоны, ферменты.

Стресс входит в число наиболее значимых факторов, нарушающих гомеостаз у животных и человека. Под воздействием стресс-реакции изменяется баланс биологически активных веществ, что приводит к развитию патологий. Многие отечественные и зарубежные ученые сходятся в том, что дисбаланс антиоксидантных и прооксидантных процессов - одно из первых проявлений нарушения обмена веществ под воздействием стресса (1-4). Проблема стресса в животноводстве стоит крайне остро: стресс приводит к уменьшению продуктивности, снижению качества продукции, росту заболеваемости животных, уменьшению темпов воспроизводства и, как следствие, рентабельности животноводства (5-7). Благополучие животных (animal welfare) важно не только в контексте гуманизации хозяйственной деятельности человека, но и с точки зрения экономической выгоды, и потому привлекает внимание исследователей и практиков.

К сожалению, приходится констатировать, что в животноводстве технологический стресс сопутствует практически всем этапам производственного процесса. Он возникает во время транспортировки животных, при выполнении операций по кормлению и уходу, может наблюдаться при резких сменах рационов и условий содержания, на его развитие может повлиять изменение условий микроклимата и многие другие факторы (8-10). Помимо технологического стресса у животных возникает физиологический стресс, обусловленный наиболее напряженными периодами их эксплуатации, таких, например, как беременность и роды $(11,12)$.

В норме свободнорадикальное окисление обеспечивает нормальное функционирование клетки и осуществление в ней обменных процессов $(13,14)$. При патологическом изменении этих процессов запускается механизм цепного поражения клеток и тканей из-за способности свободных радикалов нарушать структуру и целостность биологических мембран (1517). Интенсификация свободнорадикальных реакций, выходящих из-под контроля системы антиоксидантной защиты, - наиболее вероятный механизм поражения организма при стрессовой нагрузке $(18,19)$.

В настоящее время животноводство ориентировано на повышение благополучия поголовья. Однако из-за того, что объемы продукции необходимо увеличивать при минимальных затратах, не всегда удается изменять технологии таким образом, чтобы уменышить количество стресс-факторов и силу их воздействия (20). Следовательно, сохраняется целесообразность фармакологической профилактики нарушений, вызываемых стрессом. Механизм действия современных средств и методов коррекции изменений, обусловленных негативным воздействием стресс-факторов на организм, должен быть эффективным и безопасным $(21,22)$.

В настоящей работе на основании оценки состояния системы антиоксидантной защиты, кортизолового и тироксинового статуса при моделировании технологического стресса мы впервые показали антистрессовый эффект разработанных антиоксидантных и антистрессовых препаратов.

Нашей целью было изучение влияния экспериментально смоделированной стресс-реакции на динамику показателей свободнорадикального окисления и антиоксидантной защиты у кроликов на фоне коррекции комплексными антиоксидантными и антистрессовыми препаратами. 
Методика. По принципу аналогов сформировали 6 групп кроликов (Oryctolagus cuniculus L.) породы советская шиншилла (возраст 6-7 мес, по 20 животных в группе). Технологический стресс моделировали, помещая подопытных животных в специально изготовленные модули площадью 0,12 м $^{2}$ на 5 сут (иммобилизация с ограничением пространства). Кроликам из II группы внутримышечно вводили препарат для коррекции стрессовых состояний у сельскохозяйственных животных (антистрессовый препарат) (23) в дозе 3,9 мг/кг живой массы (по действующему веществу) за 3 сут и за 1 ч до иммобилизации, по аналогичной схеме в III группе применяли препарат Мебисел (24) в дозе 6,0 мг/кг, в IV группе - антиоксидантный препарат для животных (25) в дозе 5,4 мг/кг, а в V группе - Полиоксидол в дозе 5,0 мг/кг (26). В I группе препаратов не применяли (эти кролики служили контролем). Все использованные препараты разработаны на кафедре терапии и фармакологии Ставропольского ГАУ. Испытуемые препараты, которые использовали во II и III группах, содержат действующие вещества с антистрессовым эффектом, примененные в IV и V группах обладают антиоксидантным действием.

Кровь для анализа брали из ушной вены до введения препаратов, непосредственно перед иммобилизацией, через 1 сут и 5 сут после начала моделирования стресса и через 5 сут после завершения ограничения подвижности животных, в эти же сроки животных взвешивали. В крови определяли концентрацию кортизола, тироксина, показатели перекисного окисления липидов и антиоксидантной защиты. Количество кортизола измеряли на автоматическом иммуноферментном анализаторе Chem Well Combi («Awareness Technology», США) с наборами реактивов (ООО «Хема», Россия). При определении показателей антиоксидантной защиты применяли описанные методики (27). Для измерения активности каталазы, супероксиддисмутазы, глутатионпероксидазы, содержания восстановленного глутатиона и концентрации продуктов перекисного окисления липидов использовали спектрофотометр UNICO 2800 UV/VIS («United Products \& Instruments, Inc.», США).

При обработке данных рассчитывали средние $(M)$ и стандартные ошибки средних $( \pm \mathrm{SEM})$. Достоверность различий оценивали по $t$-критерию Стьюдента. Различия считали статистически значимыми при $\mathrm{p} \leq 0,05$.

Результаты. Известно, что иммобилизация с ограничением пространства - один из наиболее сильных стресс-факторов (28-31). Анализ данных, полученных при лабораторном исследовании крови, указывает на то, что иммобилизационный стресс, смоделированный у кроликов в лабораторных условиях, приводит к многократному повышению количества кортизола и снижению продукции тироксина (табл. 1). Установлено, что у животных, которых не подвергали профилактической обработке, концентрация кортизола в крови за 1 сут нахождения в ограниченном пространстве возросла в 5,8 раза и оставалась высокой в течение всего эксперимента. Необходимо отметить, что в крови особей, которым перед провокацией стрессовой реакции вводили антистрессовые и антиоксидантные препараты, также зафиксировали значительное повышение уровня кортизола и пик такого увеличения приходился на 1-е сут воздействия стресс-фактора. Но при этом даже на пике этот показатель был меньше, чем в контроле: во II группе - на 65,2 \%, в III - на 44,7 \%, в IV - на $22,9 \%$ и в V - на $29,5 \%$, причем разница между группами на этом и последующих этапах эксперимента носила статистически достоверный характер (p $\leq 0,05)$. После прекращения воздействия стресс-фактора тенденция к нормализации количества кортизола в крови была более выражена у животных, которых 
проходили фармакологическую подготовку. Через 5 сут после завершения иммобилизации у кроликов из I группы зафиксировали самые высокие значения по этому параметру (они превышали показатели в остальных группах в 1,8 раза и более).

Нами установлено, что применение антистрессовых и антиоксидантных препаратов способствовало увеличению количества тироксина в крови кроликов (см. табл. 1). Через 3 сут после введения препаратов концентрация этого гормона у животных во II группе возросла на 42,3 \%, в III группе - на 48,6 \%, в IV и V группах - соответственно на 9,1 и $31,1 \%$. После перемещения кроликов в ограниченное пространство количество тироксина во всех группах снизилось, причем в большинстве из них более чем на $50 \%$. В пробах крови, полученных через 5 сут после завершения иммобилизации, концентрация гормона увеличилась во всех группах. В контроле этот показатель был статистически достоверно меныше: относительно II группы - на 64,6 \% (p $\leq 0,01)$, III - на 82,7 \% (p $\leq 0,01)$, IV и $\mathrm{V}-$ соответственно на 37,7 ( $\mathrm{p} \leq 0,01)$ и $27,2 \%$ ( $\mathrm{p} \leq 0,02)$. Динамика содержания тироксина свидетельствует о том, что стресс-реакция оказывает выраженное тормозящее влияние на его выработку, а применяемые препараты имеют значимый профилактический эффект.

1. Концентрация гормонов стресса и продуктов перекисного окисления липидов в крови кроликов (Oryctolagus cuniculus L.) породы советская шиншилла при моделировании стресса иммобилизации $(M \pm \mathrm{SEM}, n=20)$

\begin{tabular}{|c|c|c|c|c|c|}
\hline Группа & $\begin{array}{l}\text { Кортизол, } \\
\text { нмоль/л }\end{array}$ & $\begin{array}{l}\text { Тироксин, } \\
\text { нмоль/л }\end{array}$ & $\begin{array}{l}\text { Диеновые конъюгаты, } \\
\text { ед. OD/мг липидов }\end{array}$ & $\begin{array}{l}\text { Малоновый } \\
\text { диальдегид, } \\
\text { мкмоль/л }\end{array}$ & $\begin{array}{l}\text { Основания Шиф- } \\
\text { фа, отн. ед/мл сы- } \\
\text { воротки }\end{array}$ \\
\hline \multicolumn{6}{|c|}{ До в ведения препаратов } \\
\hline I & $38,26 \pm 2,69$ & $27,18 \pm 1,94$ & $0,33 \pm 0,03$ & $1,29 \pm 0,09$ & $0,30 \pm 0,02$ \\
\hline II & $34,67 \pm 2,12$ & $29,43 \pm 2,15$ & $0,29 \pm 0,02$ & $1,17 \pm 0,08$ & $0,27 \pm 0,02$ \\
\hline III & $37,19 \pm 2,74$ & $26,83 \pm 1,71$ & $0,34 \pm 0,03$ & $1,31 \pm 0,09$ & $0,30 \pm 0,03$ \\
\hline IV & $35,72 \pm 2,44$ & $33,62 \pm 1,98$ & $0,31 \pm 0,02$ & $1,24 \pm 0,08$ & $0,31 \pm 0,02$ \\
\hline V & $39,12 \pm 2,81$ & $28,52 \pm 2,03$ & $0,34 \pm 0,03$ & $1,32 \pm 0,09$ & $0,28 \pm 0,02$ \\
\hline \multicolumn{6}{|c|}{ Перед имм обилизацие й } \\
\hline I & $40,73 \pm 2,56$ & $25,44 \pm 1,58$ & $0,34 \pm 0,03$ & $1,32 \pm 0,09$ & $0,31 \pm 0,02$ \\
\hline II & $22,21 \pm 1,7$ & $42,27 \pm 2,99^{a}$ & $0,27 \pm 0,02$ & & $0,27 \pm 0,02$ \\
\hline III & $24,96 \pm 1,94^{\mathrm{a}}$ & $39,87 \pm 3,11^{\mathrm{a}}$ & $0,30 \pm 0,02$ & $1,28 \pm 0,09$ & $0,31 \pm 0,02$ \\
\hline IV & $36,09 \pm 2,48^{\mathrm{e}}$ & $36,70 \pm 2,78^{a}$ & $0,24 \pm 0,02^{c}$ & $1,20 \pm 0,09$ & $0,29 \pm 0,02$ \\
\hline V & $38,47 \pm 2,61^{\mathrm{e}}$ & $37,39 \pm 2,63^{a}$ & $0,21 \pm 0,02^{\mathrm{d}}$ & $1,23 \pm 0,08$ & $0,26 \pm 0,02$ \\
\hline \multicolumn{6}{|c|}{ Че ре 31 сут после начала им мобилизаци и } \\
\hline I & $238,23 \pm 16,89$ & $13,47 \pm 1,00$ & $0,62 \pm 0,05$ & $1,57 \pm 0,11$ & $0,35 \pm 0,03$ \\
\hline II & $144,19 \pm 11,17 \mathrm{a}$ & $20,53 \pm 1,46^{\mathrm{a}}$ & $0,46 \pm 0,04 \mathrm{a}$ & & $=0,02$ \\
\hline III & $131,74 \pm 9,75^{\mathrm{a}}$ & $23,66 \pm 1,59^{a}$ & $0,42 \pm 0,03^{a}$ & $1,43 \pm 0,09$ & $, 33 \pm 0,03$ \\
\hline IV & $183,51 \pm 13,90^{\mathrm{d}}$ & $17,32 \pm 1,34 \mathrm{c}$ & $0,37 \pm 0,03^{a}$ & $1,25 \pm 0,08^{a}$ & $0,27 \pm 0,02^{\mathrm{a}}$ \\
\hline V & $167,91 \pm 12,07 \mathrm{c}$ & $19,48 \pm 1,48^{\mathrm{a}}$ & $0,33 \pm 0,02^{\mathrm{d}}$ & $1,22 \pm 0,08^{b}$ & $0,26 \pm 0,02^{\mathrm{a}}$ \\
\hline \multicolumn{6}{|c|}{ Чере 35 сут после начала иммобилизации } \\
\hline I & $181,14 \pm 12,93$ & $9,93 \pm 0,72$ & $0,87 \pm 0,07$ & $2,01 \pm 0,15$ & $0,67 \pm 0,05$ \\
\hline II & $74,60 \pm 5,21^{\mathrm{a}}$ & $16,58 \pm 1,26^{\mathrm{a}}$ & $0,62 \pm 0,05^{\mathrm{a}}$ & $1,73 \pm 0,13$ & $0,56 \pm 0,04$ \\
\hline III & $86,89 \pm 6,34 a$ & $18,21 \pm 1,33^{\mathrm{a}}$ & $0,58 \pm 0,04 \mathrm{a}$ & $1,59 \pm 0,11^{\mathrm{a}}$ & $0,52 \pm 0,04 \mathrm{a}$ \\
\hline IV & $111,24 \pm 7,72^{\mathrm{d}}$ & $12,97 \pm 0,93^{d}$ & $0,41 \pm 0,03^{\mathrm{d}}$ & $1,41 \pm 0,10^{\mathrm{a}}$ & $0,48 \pm 0,04^{\mathrm{a}}$ \\
\hline V & $100,76 \pm 7,14^{b}$ & $13,22 \pm 1,18^{\mathrm{c}}$ & $0,45 \pm 0,03^{\mathrm{d}}$ & $1,36 \pm 0,10^{\mathrm{b}}$ & $0,41 \pm 0,03^{b}$ \\
\hline \multicolumn{6}{|c|}{ Че е е 35 сут посл е 3 авыше ния им мобилизаци и } \\
\hline I & $149,12 \pm 11,65$ & $11,84 \pm 0,89$ & $0,59 \pm 0,04$ & $1,88 \pm 0,14$ & $0,72 \pm 0,05$ \\
\hline II & $48,57 \pm 3,65^{\mathrm{a}}$ & $19,49 \pm 1,39^{\mathrm{a}}$ & $0,43 \pm 0,03^{\mathrm{a}}$ & $1,49 \pm 0,10^{\mathrm{a}}$ & $0,59 \pm 0,04^{\mathrm{a}}$ \\
\hline III & $60,08 \pm 4,62^{\mathrm{a}}$ & $21,63 \pm 1,70^{\mathrm{a}}$ & $0,39 \pm 0,03^{a}$ & $1,42 \pm 0,10^{\mathrm{a}}$ & $0,46 \pm 0,03^{b}$ \\
\hline IV & $81,24 \pm 5,76^{\mathrm{d}}$ & $15,06 \pm 1,12^{\mathrm{d}}$ & $0,36 \pm 0,03^{a}$ & $1,31 \pm 0,09^{a}$ & $0,39 \pm 0,03^{b}$ \\
\hline V & $76,43 \pm 5,53^{d}$ & $16,31 \pm 1,21^{\mathrm{c}}$ & $0,32 \pm 0,02^{\mathrm{b}}$ & $1,28 \pm 0,09^{a}$ & $0,33 \pm 0,03^{\mathrm{d}}$ \\
\hline \multicolumn{6}{|c|}{$\begin{array}{l}\text { П р и м е ч а н и е. а - между этой и I группой разница статистически значима; b - между этой, I и II } \\
\text { группами разница статистически значима; с - между этой, I и III группами разница статистически зна- } \\
\text { чима; d - между этой, I, II и III группами разница статистически значима; е - между этой II и III груп- } \\
\text { пами разница статистически значима }(\mathrm{p} \leq 0,05) \text {. }\end{array}$} \\
\hline
\end{tabular}

Установлено, что воздействие стресс-фактора сопровождается интенсификацией перекисного окисления липидов, о чем свидетельствует изменение концентрации продуктов пероксидации. Концентрация диено- 
вых конъюгатов в контрольной группе за 5 сут иммобилизации увеличилась в 2,5 раза. В условиях 5-суточной иммобилизации у животных из II группы, которые получили антистрессовый препарат, показатель возрос на 82,3 \%, у кроликов, которым назначали Мебисел, - на 93,3 \%, в IV группе, где использовали еще один антиоксидантный препарат, - на 70,8 \%, а в V группе, в которой вводили Полиоксидол, произошло более чем 2-кратное увеличение. После завершения иммобилизации концентрация диеновых конъюгатов уменьшалась во всех пяти группах, но в контрольной группе этот показатель был достоверно $(\mathrm{p} \leq 0,05)$ выше, чем в опытных.

Сравнивая значения для малонового диальдегида между группами, стоит отметить, что на протяжении всего эксперимента самое высокое содержание этого продукта пероксидации было у контрольных особей. В пробах крови, полученных через 5 сут после завершения иммобилизации, концентрация малонового диальдегида в I группе была на 20,7 \% (p = 0,16) выше, чем во II, на 24,5 \% (p $\leq 0,05)$ выше, чем в III, на 30,3 (p $\leq 0,05)$ и $31,9 \%$ ( $\leq \leq 0,05)$, выше, чем соответственно в IV и V группах (см. табл. 1).

Динамика накопления флуоресцирующих оснований Шиффа в крови животных из всех групп практически не изменялась по истечении 3 сут с момента введения препаратов. Через 1 сут после начала моделирования стрессового воздействия стали проявляться различия. За 5 сут иммобилизации концентрация оснований Шиффа в I группе была на 16,4 \% выше, чем во II $((\mathrm{p}=0,09)$, на 22,4 \% выше, чем в III $(\mathrm{p}=0,02)$, на 28,4 \% выше, чем в IV (p $\leq 0,01)$, и на $38,8 \%$ выше, чем в V группе (p $\leq 0,01)$ (см. табл. 1).

Оценивая динамику показателей ферментативного звена системы антиоксидантной защиты, отметим, что применение антиоксидантных и антистрессовых препаратов привело к повышению активности ферментов (табл. 2). По завершении эксперимента активность глутатионпероксидазы в первой I группе была на 48,2 \% меньше, чем во второй (p $\leq 0,01)$, на $76,8 \%(\mathrm{p} \leq 0,01)$ - чем в III, в 2,0 и 2,1 раза - чем в IV и V. Такую разницу можно объяснить тем, что в состав действующего вещества всех примененных препаратов входит селенсодержащее соединение.

2. Показатели системы антиоксидантной защиты крови и динамика живой массы кроликов (Oryctolagus cuniculus L.) породы Советская шиншилла при моделировании стресса иммобилизации $(M \pm \mathrm{SEM}, n=20)$

\begin{tabular}{|c|c|c|c|c|c|}
\hline Группа & $\begin{array}{l}\text { ГПО, мкмоль G- } \\
\mathrm{SH} /\left(л \cdot \text { мин } \cdot 10^{3}\right)\end{array}$ & $\begin{array}{l}\text { СОД, } \\
\text { ед. акт/мг } \\
\text { гемоглобина }\end{array}$ & $\begin{array}{l}\text { Каталаза, мкмоль } \\
\mathrm{H}_{2} \mathrm{O}_{2} /\left(л \cdot \text { мин } \cdot 10^{3}\right)\end{array}$ & $\begin{array}{l}\text { Глутатион вос- } \\
\text { становленный, } \\
\text { ммоль/л }\end{array}$ & $\begin{array}{l}\text { Живая } \\
\text { масса, кг }\end{array}$ \\
\hline \multicolumn{6}{|c|}{ До в ведения препаратов } \\
\hline I & $7,39 \pm 0,53$ & $4,72 \pm 0,36$ & $24,13 \pm 1,78$ & $0,31 \pm 0,02$ & $3,58 \pm 0,26$ \\
\hline II & $8,43 \pm 0,64$ & $5,11 \pm 0,42$ & $23,27 \pm 1,51$ & $0,35 \pm 0,03$ & $3,44 \pm 0,23$ \\
\hline III & $7,87 \pm 0,57$ & $4,93 \pm 0,39$ & $23,79 \pm 1,82$ & $0,33 \pm 0,03$ & $3,61 \pm 0,29$ \\
\hline IV & $8,18 \pm 0,69$ & $5,02 \pm 0,46$ & $24,42 \pm 1,96$ & $0,34 \pm 0,03$ & $3,49 \pm 0,24$ \\
\hline V & $7,34 \pm 0,56$ & $4,81 \pm 0,34$ & $22,94 \pm 1,35$ & $0,29 \pm 0,02$ & $3,70 \pm 0,31$ \\
\hline \multicolumn{6}{|c|}{ Пере д и м мобилиза ци ей } \\
\hline I & $7,22 \pm 0,36$ & $4,64 \pm 0,39$ & $24,05 \pm 1,66$ & $0,30 \pm 0,02$ & $3,64 \pm 0,30$ \\
\hline II & $10,31 \pm 0,76^{\mathrm{a}}$ & $5,63 \pm 0,58$ & $23,89 \pm 1,47$ & $0,35 \pm 0,03$ & $3,42 \pm 0,28$ \\
\hline III & $11,13 \pm 0,69^{\mathrm{a}}$ & $5,49 \pm 0,43$ & $24,01 \pm 1,59$ & $0,35 \pm 0,03$ & $3,65 \pm 0,32$ \\
\hline IV & $12,41 \pm 0,88^{\mathrm{a}}$ & $6,18 \pm 0,53^{a}$ & $26,95 \pm 1,91$ & $0,37 \pm 0,03$ & $3,57 \pm 0,29$ \\
\hline V & $12,93 \pm 0,82^{\mathrm{b}}$ & $5,92 \pm 0,55$ & $27,11 \pm 2,13$ & $0,32 \pm 0,03$ & $3,72 \pm 0,34$ \\
\hline \multicolumn{6}{|c|}{ Ч е ре 31 сут посл е начала и м мобил изаци и } \\
\hline I & $5,07 \pm 0,42$ & $3,22 \pm 0,25$ & $19,47 \pm 1,28$ & $0,26 \pm 0,02$ & $3,37 \pm 0,21$ \\
\hline II & $10,56 \pm 0,71^{\mathrm{a}}$ & $5,41 \pm 0,44^{\mathrm{a}}$ & $21,60 \pm 1,43$ & $0,30 \pm 0,02$ & $3,31 \pm 0,29$ \\
\hline III & $13,22 \pm 0,94^{\mathrm{b}}$ & $5,78 \pm 0,50^{\mathrm{a}}$ & $22,11 \pm 1,52$ & $0,32 \pm 0,02^{\mathrm{a}}$ & $3,48 \pm 0,27$ \\
\hline IV & $14,49 \pm 1,09^{b}$ & $5,89 \pm 0,52^{\mathrm{a}}$ & $24,76 \pm 1,73^{\mathrm{a}}$ & $0,35 \pm 0,03^{\mathrm{a}}$ & $3,34 \pm 0,31$ \\
\hline V & $15,01 \pm 1,03^{b}$ & $6,14 \pm 0,57^{a}$ & $25,31 \pm 1,80^{\mathrm{a}}$ & $0,30 \pm 0,02$ & $3,51 \pm 0,33$ \\
\hline \multicolumn{6}{|c|}{ Чере 5 сут после начала иммобилизаци и } \\
\hline I & $4,68 \pm 0,34$ & $2,95 \pm 0,23$ & $14,53 \pm 1,12$ & $0,20 \pm 0,02$ & $3,09 \pm 0,24$ \\
\hline II & $9,69 \pm 0,67^{\mathrm{a}}$ & $4,26 \pm 0,29^{a}$ & $16,82 \pm 1,20$ & $0,27 \pm 0,02^{\mathrm{a}}$ & $3,24 \pm 0,27$ \\
\hline
\end{tabular}




\begin{tabular}{|c|c|c|c|c|c|}
\hline & & & & \multicolumn{2}{|c|}{ Продолжение таблицы 2} \\
\hline III & $10,92 \pm 0,83^{\mathrm{a}}$ & $4,71 \pm 0,33^{\mathrm{a}}$ & $18,63 \pm 1,36^{a}$ & $0,30 \pm 0,02^{\mathrm{a}}$ & $3,51 \pm 0,32$ \\
\hline IV & $12,45 \pm 0,88^{\mathrm{b}}$ & $5,04 \pm 0,40^{\mathrm{a}}$ & $21,26 \pm 1,49^{\mathrm{b}}$ & $0,32 \pm 0,02^{\mathrm{a}}$ & $3,22 \pm 0,25$ \\
\hline V & $12,95 \pm 0,96^{\mathrm{b}}$ & $5,63 \pm 0,44^{b}$ & $23,15 \pm 1,42^{\mathrm{c}}$ & $0,34 \pm 0,03^{\mathrm{a}}$ & $3,45 \pm 0,29$ \\
\hline \multicolumn{6}{|c|}{ Ч е ре 35 сут после 3 а выше ния им мобилизаци и } \\
\hline I & $6,33 \pm 0,51$ & $3,41 \pm 0,27$ & $18,49 \pm 1,54$ & $0,23 \pm 0,02$ & $3,21 \pm 0,28$ \\
\hline II & $9,38 \pm 0,59^{\mathrm{a}}$ & $4,47 \pm 0,32^{\mathrm{a}}$ & $20,88 \pm 1,41$ & $0,31 \pm 0,02^{\mathrm{a}}$ & $3,38 \pm 0,31$ \\
\hline III & $11,19 \pm 0,82^{\mathrm{a}}$ & $5,23 \pm 0,41^{\mathrm{a}}$ & $24,31 \pm 1,89^{\mathrm{a}}$ & $0,34 \pm 0,03^{\mathrm{a}}$ & $3,68 \pm 0,32$ \\
\hline IV & $12,86 \pm 0,89^{b}$ & $5,79 \pm 0,38^{\mathrm{b}}$ & $26,52 \pm 2,33^{b}$ & $0,36 \pm 0,03^{\mathrm{a}}$ & $3,40 \pm 0,26$ \\
\hline $\mathrm{V}$ & $13,13 \pm 0,97^{\mathrm{b}}$ & $6,34 \pm 0,52^{b}$ & $25,91 \pm 2,07^{\mathrm{a}}$ & $0,37 \pm 0,03^{\mathrm{a}}$ & $3,64 \pm 0,32$ \\
\hline
\end{tabular}

Активность супероксиддисмутазы ощутимо возросла в крови животных, которые получали антиоксидантные и антистрессовые препараты, при снижении этого показателя в контроле. Смоделированный технологический стресс приводил к выраженному уменьшению активности супероксиддисмутазы в крови кроликов из I (контрольной) группы. За 5 сут иммобилизации статистически достоверная разница между I и II группой составила 44,4 \% (p $\leq 0,01)$, I и III $-59,6 \%$, I и IV $-70,8 \%$ (p $\leq 0,01)$, I и $\mathrm{V}-90,8 \%(\mathrm{p} \leq 0,01)$.

После того как кроликов возвратили в привычные для них условия содержания, у них нормализовалась активностиь каталазы, но в контрольной группе этот показатель был значительно ниже, чем в остальных: разница со II группой составила $12,9 \%(\mathrm{p}=0,25)$, с III $-31,5 \%(\mathrm{p} \leq 0,02)$, с $\mathrm{IV}-43,4 \%(\mathrm{p} \leq 0,01)$ и с $\mathrm{V}-40,1 \%(\mathrm{p} \leq 0,01)$ (см. табл. 2).

Глутатион - один из важных факторов антиоксидантной защиты $(32,33)$ и критических маркеров оценки ее функционирования $(34,35)$. После 5-суточной иммобилизации кроликов концентрация восстановленного глутатиона в I группе была на $35 \%$ ниже, чем во II (p $\leq 0,02)$, на 50 \% $(\mathrm{p} \leq 0,01)$ - по сравнению с III, на $60 \%(\mathrm{p} \leq 0,01)$ и $70 \%(\mathrm{p} \leq 0,01)-$ coответственно с IV и V группами (см. табл. 2).

Воздействие смоделированного технологического стресса отрицательно повлияло на динамику живой массы кроликов. Применение антиоксидантных и антистрессовых препаратов ускорило постстрессовую адаптацию, что выразилось в увеличении среднесуточного прироста массы тела животных. За 5 сут, прошедших с момента прекращения ограничения подвижности, у кроликов из I группы среднесуточный прирост массы составил 24,2 г, во II $-28,4$ г, в III $-34,1$ г, в IV $-35,6$ г и в V $-38,3$ г.

Таким образом, мы установили, что развивающаяся стресс-реакция проявляется резким увеличением количества кортизола в крови - до $238,23 \pm 16,89$ нмоль/л, при этом максимальных значений показатель достигает в 1-е сут воздействия стресс-фактора. Исходя из этого, можно считать, что 1-е сут наиболее критические для течения патологического процесса при иммобилизационном стрессе у животных. Также при технологическом стрессе на протяжении всего периода его воздействия наблюдается

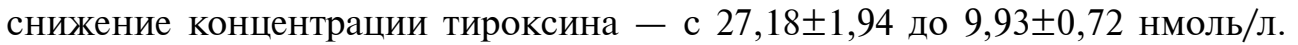
Смоделированный стресс отразился на функционировании системы антиоксидантной защиты, что проявилось уменьшением активности ферментов глутатионпероксидазы на 36,7 \%, супероксиддисмутазы на 37,9 \% и каталазы на $39,8 \%$, а также снижением концентрации восстановленного глутатиона на $35,9 \%$. Депрессивное состояние антиоксидантной системы сопровождается значительным накоплением в крови продуктов перекисного окисления липидов (диеновые конъюгаты, малоновый диальдегид и флуоресциру- 
ющие основания Шиффа). Негативное воздействие стресса на организм кроликов также выражается в уменьшении живой массы на 490 г за 5 сут иммобилизации.

Применение четырех разработанных нами антистресовых препаратов для профилактики негативных последствий технологического стресса способствует стабилизации уровня кортизола, тироксина, активности антиоксидантных ферментов и концентрации продуктов перекисного окисления липидов. При этом транквилизаторы в большей степени снижают концентрацию кортизола и нормализуют количество тироксина, что способствует улучшению показателей свободнорадикального окисления и антиоксидантной защиты. Антиоксидантные препараты активизируют функцию ферментативного звена антиоксидантной защиты и снижают накопление продуктов перекисного окисления липидов в организме кроликов, в результате чего уменьшается количество тироксина и кортизола. Это позволяет рекомендовать разработанные средства для фармакологической профилактики технологического стресса.

Итак, установлено, что при экспериментальном воспроизведении стресс-реакции (иммобилизация) у кроликов развивается окислительный стресс, который выражается в возрастании концентрации продуктов перекисного окисления липидов в крови: диеновых конъюгатов, малонового диальдегида и флуоресцирующих оснований Шиффа, а также в уменьшении активности глутатионпероксидазы, супероксиддисмутазы и каталазы на фоне увеличения концентрации кортизола и снижения - тироксина. Применение новых лекарственных средств для животных - препарата для коррекции стрессовых состояний у сельскохозяйственных животных, антиоксидантного препарата для животных, Мебисела и Полиоксидола эффективно профилактирует технологический стресса и может быть использовано в практической ветеринарии. Нормализация антиоксидантного статуса у кроликов приводит к уменьшению уровня кортизола и повышению концентрации тироксина в крови. С учетом результатов выполненного нами исследования можно рекомендовать включение препаратов, обладающих антиоксидантной активностью, в схемы профилактики технологического стресса у животных.

\footnotetext{
ФГБОУ ВО Ставропольский государственный аграрный университет,

355017 Россия, г. Ставрополь, пер. Зоотехнический, 12,

e-mail: kireev-iv@mail.ru $\bowtie$, orobets@yandex.ru, chernova_ts@mail.ru,

zinchenko444@mail.ru
}

Поступила в редакциюю

Sel'skokhozyaistvennaya biologiya [Agricultural Biology], 2019, V. 54, № 4, pp. 767-776

\title{
DYNAMICS OF OXIDATIVE STATE INDICATORS IN RABBITS (Oryctolagus cuniculus L.) UNDER SIMULATED TECHNOLOGICAL STRESS AND ITS PHARMACOLOGICAL CORRECTION
}

\author{
I.V. Kireev, V.A. Orobets, T.S. Denisenko, D.A. Zinchenko
}

\begin{abstract}
Stavropol State Agrarian University, 12, per. Zootechnicheskii, Stavropol, 355017 Russia, e-mail kireev-iv@mail.ru ( $₫$ corresponding author), orobets@yandex.ru,chernova_ts@mail.ru, zinchenko444@mail ORCID:

Kireev I.V. orcid.org/0000-0003-0723-4515

Orobets V.A. orcid.org/0000-0002-4774-263X

Denisenko T.S. orcid.org/0000-0002-6185-9199

Zinchenko D.A. orcid.org/0000-0001-8674-5449
\end{abstract}

The authors declare no conflict of interests

Received August 6, 2018

doi: 10.15389/agrobiology.2019.4.767eng

Abstract

Stress is the most important livestock problem, causing great damage to the industry. The 
emergence of technological stress contributes to a large number of factors, from transportation to conditions of keeping and feeding. The development of pathological processes under stress intensifies free radical processes in the body, with the excessive formation of free radicals. Therefore, there is a need in drugs based on substances with high antioxidant activity to pharmacologically correct technological stress in farm animals. In our experiment, we simulated conditions of technological stress in Soviet chinchilla rabbits aged 6-7 months by immobilization. Antioxidant and anti-stress drugs developed at Stavropol State Agrarian University were used as agents. Group 1 of animals was control. Rabbits of group 2 received Drug to correct stress in farm animals (Patent RU 2428992 of 09.20.11), group 3 received Mebisel (Patent RU 2418579 of 05.20.11), these drugs have a pronounced anti-stress effect; group 4 received Antioxidant preparation for animals (Patent RU 2435572 of 12.10.11) and group 5 received Polyoxidol (Patent RU 2538666 of 01.10.15), the antioxidants. Blood levels of cortisol, thyroxine, lipid peroxidation and antioxidant protection were assessed. It was shown that immobilization of experimental animals provokes a significant production of cortisol $(5,8$ times higher) and a decrease in the thyroxine level up to $60,9 \%(\mathrm{p} \leq 0,01)$, the blood concentration of diene conjugates increases 2.6 times $(\mathrm{p} \leq 0,01)$, malondialdehyde by $55,8 \%(\mathrm{p} \leq 0,01)$ and fluorescent Schiff bases 2,2 times $(\mathrm{p} \leq 0,01)$. The restricted mobility adversely affectes the activity of antioxidative defence enzymes, with a significant decrease in glutathione peroxidase activity (by $35.2 \%$ ), superoxide dismutase (by $36.4 \%$ ), catalase (by $40.7 \%)(p \leq 0.01)$ and the content of reduced glutathione (by $33.3 \%, \mathrm{p} \leq 0.01$ ). Administration of antioxidant and antistress preparations contributes to the normalization of the studied parameters in experimental animals, the values of which during the experiment were statistically significantly different from the data recorded in the control group. In the dynamics of activity of antioxidant enzymes and products of lipid peroxidation, there were significant differences between the indices of animals from the control group and rabbits which received preventive agents. The animals of the control group showed a progressive increase in the concentration of lipoperoxides and a decrease in the activity of glutathione peroxidase, superoxide dismutase, catalase, and reduced glutathione. The use of antioxidant and antistress drugs three days before immobilization contributed to the optimization of these indicators. The applied prevention regimens allowed reduction of negative impact of stress, which resulted in statistically significant differences in the numerical values of the results of the laboratory blood test of animals from the groups 2, 3, 4 and 5 conoared to the control. At the end of the experiment glutathione peroxidase was 48.2-107.4\% higher $(\mathrm{p} \leq 0.01)$, superoxide dismutase $31.1-85.9 \%$ higher $(\mathrm{p} \leq 0.01)$, catalase 12.9 $40.1 \%$ higher ( $\leq 0.05$ in groups III, IV and V), while glutathione was 34.8-60.8 \% lower $(\mathrm{p} \leq 0.01)$, thyroxine 27.2-82.7 \% lower ( $\mathrm{p} \leq 0.05$ ). The cortisol level declined by 83.5-207.0\% ( $\leq \leq 0.01)$, diene conjugates by 37.2-84.3\% ( $\mathrm{p} \leq 0.01$ ), malondialdehyde by 26.1-46.9\% ( $\mathrm{p} \leq 0.05$ ), and fluorescent Schiff bases by 22.03-118.1\% ( $\mathrm{p} \leq 0.05$ ). The use of drugs accelerates post-stress adaptation, which was expressed in an increase in the average daily weight gain of rabbits from experimental groups, i.e. $28 \mathrm{~g}$ for group 2, $34 \mathrm{~g}$ for group 3, $36 \mathrm{~g}$ for group 4, and $38 \mathrm{~g}$ for group 5 compared to $24 \mathrm{~g}$ for the control group. Our results on the stress-born hormone dynamics are indicative of significant changes in the antioxidant defense system functioning and lipid peroxidation. These data allow us to recommend the developed tranquilizers and antioxidants for physiological correction of technological stresses in animals.

Keywords: Oryctolagus cuniculus L., rabbits, technological stress, immobilization, antistress agent, antioxidant preparation, antioxidant system, lipid peroxidation, hormones, enzymes.

\section{REFEREN C ES}

1. Pertsov S.S., Kalinichenko L.S., Koplik E.V., Nagler L.G., Alinkina E.S., Kozachenko A.I. Biomeditsinskaya khimiya, 2015, 61(3): 394-399 (doi: 10.18097/PBMC20156103394) (in Russ.).

2. Chen H.J., Spiers J.G., Sernia C., Anderson S.T., Lavidis N.A. Reactive nitrogen species contribute to the rapid onset of redox changes induced by acute immobilization stress in rats. Stress, 2014, 17(6): 520-527 (doi: 10.3109/10253890.2014.966264).

3. Hall J.A., Bobe G., Nixon B.K., Vorachek W.R., Hugejiletu, Nichols T., Mosher W.D., Pirelli G.J. Effect of transport on blood selenium and glutathione status in feeder lambs. Journal of Animal Science, 2014, 92(9): 4115-4122 (doi: 10.2527/jas.2014-7753).

4. Teixeira R.R., de Souza A.V., Peixoto L.G., Machado H.L., Caixeta D.C., Vilela D.D., Baptista N.B., Franci C.R., Espindola F.S. Royal jelly decreases corticosterone levels and improves the brain antioxidant system in restraint and cold stressed rats. Neuroscience Letters, 2017, 655: 179-185 (doi: 10.1016/j.neulet.2017.07.010).

5. Veremei E.I., Rukol' V.M., Zhurba V.A., Komarovskii V.A., Khovailo V.A. Uchenye zapiski uchrezhdeniya obrazovaniya Vitebskaya ordena «Znak pocheta» gosudarstvennaya akademiya veterinarnoi meditsiny, 2011, 47(2): 143 (in Russ.).

6. Megahed G.A., Anwar M.M., Wasfy S.I., Hammadeh M.E. Influence of heat stress on the cortisol and oxidant-antioxidants balance during oestrous phase in buffalo-cows (Bubalus bubalis): thermo-protective role of antioxidant treatment. Reproduction in Domestic Animals, 2008, 43(6): 672-677 (doi: 10.1111/j.1439-0531.2007.00968.x). 
7. Sejian V., Maurya V.P., Naqvi S.M. Effect of thermal stress, restricted feeding and combined stresses (thermal stress and restricted feeding) on growth and plasma reproductive hormone levels of Malpura ewes under semi-arid tropical environment. Journal of Animal Physiology and Animal Nutrition, 2011, 95(2): 252-258 (doi: 10.1111/j.1439-0396.2010.01048.x).

8. Abd El-Hack M.E., Khafaga A.F., Arif M., Taha A.E., Noreldin A.E. Stress biomarkers and proteomics alteration to thermal stress in ruminants: a review. Journal of Thermal Biology, 2019, 79: 120-134 (doi: 10.1016/j.jtherbio.2018.12.013).

9. Smid A.C., Weary D.M., Bokkers E.A.M., von Keyserlingk M.A.G. Short communication: The effects of regrouping in relation to fresh feed delivery in lactating Holstein cows. Journal of Dairy Science, 2019, 102 (7): 6545-6550 (doi: 10.3168 / jds.2018-16232).

10. Souza-Cácares M.B., Fialho A.L.L., Silva W.A.L., Cardoso C.J.T., Pöhland R., Martins M.I.M., Melo-Sterza F.A. Oocyte quality and heat shock proteins in oocytes from bovine breeds adapted to the tropics under different conditions of environmental thermal stress. Theriogenology, 2019, 130: 103-110 (doi: 10.1016/j.theriogenology.2019.02.039).

11. Malašauskienė D., Televičius M., Juozaitienė V., Antanaitis R. Rumination time as an indicator of stress in the first thirty days after calving. Polish Journal of Veterinary Sciences, 2019, 22(2): 363-368 (doi: 10.24425/pjvs.2019.129229).

12. Nagel C., Aurich C., Aurich J. Stress effects on the regulation of parturition in different domestic animal species. Animal Reproduction Science, 2019, 207: 153-161 (doi: 10.1016/j.anireprosci.2019.04.011).

13. Lushchak V.I. Free radicals, reactive oxygen species, oxidative stress and its classification. Chemico-Biological Interactions, 2014, 224: 164-175 (doi: 10.1016/j.cbi.2014.10.016).

14. Vikram D.S., Rivera B.K., Kuppusamy P. In vivo imaging of free radicals and oxygen. Methods in Molecular Biology, 2010, 610: 3-27 (doi: 10.1007/978-1-60327-029-8_1).

15. Nikitina E.V., Romanova N.K. Vestnik Kazanskogo tekhnologicheskogo universiteta, 2010, 10: 375-381 (in Russ.).

16. Iannitti T., Rottigni V., Palmieri B. Role of free radicals and antioxidant defences in oral cavity-related pathologies. Journal of Oral Pathology \& Medicine, 2012, 41(9): 649-661 (doi: 10.1111/j.1600-0714.2012.01143.x).

17. Pratt D.A., Tallman K.A., Porter N.A. Free radical oxidation of polyunsaturated lipids: new mechanistic insights and the development of peroxyl radical clocks. Accounts of Chemical Research, 2011, 44(6): 458-467 (doi: 10.1021/ar200024c).

18. Meshchaninov V.N., Shcherbakov D.L. Kazanskii meditsinskii zhurnal, 2015, 96(5): 843-849 (doi: 10.17750/KMJ2015-843) (in Russ.).

19. Flerov M.A., V'yushina A.V. Rossiiskii fiziologicheskii zhurnal im. I.M. Sechenova, 2011, 97(9): 898-902 (in Russ.).

20. Lyapin O.A., Lyapina V.O. Izvestiya Orenburgskogo gosudarstvennogo agrarnogo universiteta, 2016, 2(58): 161-165 (in Russ.).

21. Dobson H., Fergani C., Routly J.E., Smith R.F. Effects of stress on reproduction in ewes. Animal Reproduction Science, 2012, 130(3-4): 135-140 (doi: 10.1016/j.anireprosci.2012.01.006).

22. Ekiz B., Ekiz E.E., Kocak O., Yalcintan H., Yilmaz A. Effect of pre-slaughter management regarding transportation and time in lairage on certain stress parameters, carcass and meat quality characteristics in Kivircik lambs. Meat Science, 2012, 90(4): 967-976 (doi: 10.1016/j.meatsci.2011.11.042).

23. Kireev I.V., Orobets V.A., Skripkin V.S., Kovalev P.F. Preparat dlya korrektsii stressovykh sostoyanii u sel'skokhozyaistvennykh zhivotnykh. Pat. 2428992 (RF) MPK A 61 K 33/04, A 61 K 33/00, A 61 P 25/00. FGOU VPO Stavropol'skii GAU (RF). № 2010139029/15. Zayavl. 22.09.2010. Opubl. 20.09.2011. Byul. № 26 [Stress correcting medication for farm animals. Patent 2428992 (RF) MPK $^{9}$ A 61 K 33/04, A 61 K 33/00, A 61 P 25/00. FGOU VPO Stavropol'skii GAU (RF). № 2010139029/15. Appl. 22.09.2010. Publ. 20.09.2011. Bul. № 26] (in Russ.).

24. Orobets V.A., Aksenov A.V., Aksenova I.V., Kireev I.V., Skripkin V.S., Belyaev V.A., Sevost'yanova O.I., Lavrenchuk E.I. Immunostimuliruyushchii preparat dlya normalizatsii obmena selena $i$ korrektsii stressovykh sostoyanii dlya sel'skokhozyaistvennykh zhivotnykh. Pat. 2418579 (RF) $M P K^{9} A 61 \quad K$ 31/095, A $61 \quad P$ 43/00. FGOU VPO Stavropol'skii GAU (RF). № 2010117696/15. Zayavl. 04.05.2010. Opubl. 20.05.2011. Byul. № 14 [Immunostimulating medication to normalize selenium metabolism and correct effects of stress in farm animals. Patent 2418579 (RF) MPK $^{9}$ A 61 K 31/095, A 61 P 43/00. FGOU VPO Stavropol'skii GAU (RF). № 2010117696/15. Appl. 04.05.2010. Publ. 20.05.2011. Bul. № 14] (in Russ.).

25. Kireev I.V., Orobets V.A., Skripkin V.S., Kovalev P.F. Antioksidantnyi preparat dlya zhivotnykh. Pat. 2435572 (RF) MPK A 61 K 31/00, A 61 P 39/06. FGOU VPO Stavropol'skii GAU (RF). № 2010143411/15. Zayavl. 22.10.2010. Opubl. 10.12.2011. Byul. № 34 [The antioxidant for animals. Patent 2435572 (RF) MPK $^{9}$ A 61 K 31/00, A 61 P 39/06. FGOU VPO Stavropol'skii GAU (RF). № 2010143411/15. Appl. 22.10.2010. Publ. 10.12.2011. Bul. № 34] (in Russ.).

26. Kireev I.V., Orobets V.A., Belyaev V.A., Serov A.V., Skripkin V.S., Verevkina M.N., Chernova T.S., Rakovskaya E.V. Preparat dlya normalizatsii protsessov perekisnogo okisleniya lipidov $u$ 
zhivotnykh. Pat. 2538666 (RF) MPK A $61 \mathrm{~K} 31 / 4412, A 61 \mathrm{~K} 31 / 375, A 61 \mathrm{~K} 33 / 04, A 61 P$ 3/00. OOO NPO «Yug-Biovet». № 2013111243/15. Zayavl. 12.03.13. Opubl. 10.01.15. Byul. № 1 [The remedy to normalize lipid peroxidation in animals. Patent 2538666 (RF) MPK $^{9}$ A $61 \mathrm{~K}$ 31/4412, A 61 K 31/375, A 61 K 33/04, A 61 P 3/00. OOO NPO «Yug-Biovet». № 2013111243/15. Appl. 12.03.13. Publ. 10.01.15. Bul. № 1] (in Russ.).

27. Retskii M.I., Shabunin S.V., Bliznetsova G.N., Rogacheva T.E., Ermolova T.G., Fomenko O.Yu., Bratchenko E.V., Dubovtsev V.Yu., Kaverin N.N., Tsebrzhinskii O.I. Metodicheskie polozheniya po izucheniyu protsessov svobodnoradikal'nogo okisleniya $i$ sistemy antioksidantnoi zashchity organizma [The methodology for studying free radical oxidation processes and antioxidant defense system]. Voronezh, 2010 (in Russ.).

28. Colpo A.C., de Lima M.E., Maya-Lypez M., Rosa H., Márquez-Curiel C., Galván-Arzate S., Santamaría A., Folmer V. Compounds from Ilex paraguariensis extracts have antioxidant effects in the brains of rats subjected to chronic immobilization stress. Applied Physiology, Nutrition, and Metabolism, 2017, 42(11): 1172-1178 (doi: 10.1139/apnm-2017-0267).

29. Koptev M.M., Vynnyk N.I. Morphological substantiation for acute immobilization stress-related disorders of adaptation mechanisms. Wiadomosci Lekarskie, 2017, 70(4): 767-770.

30. Kumar A., Goyal R., Prakash A. Possible GABAergic mechanism in the protective effect of allopregnenolone against immobilization stress. European Journal of Pharmacology, 2009, 602(23): 343-347 (doi: 10.1016/j.ejphar.2008.11.038).

31. Samarghandian S., Samini F., Azimi-Nezhad M., Farkhondeh T. Anti-oxidative effects of safranal on immobilization-induced oxidative damage in rat brain. Neuroscience Letters, 2017, 659: 26-32 (doi: 10.1016/j.neulet.2017.08.065).

32. Dickinson D.A., Forman H.J. Glutathione in defense and signaling: lessons from a small thiol. Annals of the New York Academy of Sciences, 2002, 973: 488-504 (doi: 10.1111/j.17496632.2002.tb04690.x).

33. Forman H.J., Zhang H., Rinna A. Glutathione: overview of its protective roles, measurement, and biosynthesis. Molecular Aspects of Medicine, 2009, 30 (1-2): 1-12 (doi: 10.1016/j.mam.2008.08.006).

34. Hepel M., Stobiecka M. Supramolecular interactions of oxidative stress biomarker glutathione with fluorone black. Spectrochimica Acta Part A: Molecular and Biomolecular Spectroscopy, 2018, 192: 146-152 (doi: 10.1016/j.saa.2017.11.017).

35. Teskey G., Abrahem R., Cao R., Gyurjian K., Islamoglu H., Lucero M., Martinez A., Paredes E., Salaiz O., Robinson B., Venketaraman V. Glutathione as a marker for human disease. Advances in Clinical Chemistry, 2018, 87: 141-159 (doi: 10.1016/bs.acc.2018.07.004). 